\title{
Review
}

\section{Nanoanalysis of the arthropod neuro-toxins}

\author{
By Terumi NAKAJIMA*),†) \\ Emeritus Professor, University of Tokyo \\ (Communicated by Takao SEKIYA, M.J.A.)
}

\begin{abstract}
Many kinds of venomous principles modulate physiological responses of mammalian signal transduction systems, on which they act selectively as enhancers, inhibitors or some other kind of effectors. These toxins become useful tools for physiological research. We have employed and characterized paralyzing toxins from the venom of spiders, insects and scorpions with a limited supply. We have developed rapid and sensitive mass spectrometric technology and applied for the identification of these toxins. Venom profiles are screened by MALDI-TOF fingerprinting analysis prior to purification of venomous components, then marked target toxins of small molecular mass (1000-5000) are characterized directly by means of mass spectrometric techniques such as Frit-FAB MS/MS, CID/PSD-TOF MS, Capil.-HPLC/Q-TOF MS/MS etc.
\end{abstract} MS.

Key words: Spider toxin; insect toxin; scorpion toxin; Frit-FAB MS/MS; CID/PSD-TOF

Introduction. Arthropod venoms are commonly utilized as both the defensive and the offensive tools for their predators or for their prey. In some cases, human and beasts casualties have resulted from a sting or bite. Arthropods as scorpions, spiders, wasps or assassin bugs are thought to be the hatefully agressive animals. However, toxic principles in their venoms reveal numerous attracting biological activities designated specifically for the target animals. Many of these toxic principles have long been unclear, with the exception being a few species like social wasps or honey bee, whose venoms are collected in large enough amounts to characterize their chemical structures. Nevertheless the arthropod toxins are not understand for many natural scientists. This article deals with recent progress on the novel neurotoxic principles of the arthropods.

During the past several years, by means of the development of analytical technology involving HPLC, mass spectrometry and NMR spectrometry, it became possible to clarify very minute amount of material, such as arthropod toxins which until now had been difficult to collect due to their venoms

*) Recipient of the Japan Academy Prize in 1994

$\dagger$ Hoshi University, 2-4-41 Ebara, Shinagawa-ku, Tokyo 142-8501, Japan (e-mail: nakajima@hoshi.ac.jp). scarcity. Accordingly, we have focused the paralyzing neurotoxins and characterized them by using the venom of spiders, scorpions and insects to disclose their structural features and their mode of action on paralysis.

First of all, venom profiles are investigated and screened by MALDI-TOF finger printing analysis prior to purification of the venom components, then marked target toxins of small molecular mass(1000$5000)$ were characterized directly by means of mass spectrometric techniques such as Frit-FAB-MS/MS, CID-PSD-TOF MS, Capil.-HPLC/Q-TOF MS/MS etc.

Mass spectrometric characterization of spider polyamine toxins, a specific blocker of glutamatergic synapses. In 1982, N. Kawai et al. first demonstrated the presence of paralytic neurotoxin in the venom of Nephilid spider (Nephila clavata; joro-gumo) and the toxic principle was a specific receptor blocker of glutaminergic synapses. ${ }^{1)}$ The toxin which was named joro spider toxin (JSTX), blocks the glutamate receptors in the crustacean neuromuscular synapse postsynaptically. JSTX blocks quisqualate-AMPA type glutamate receptors not only in invertebrates but also vertebrates. In the initial research, JSTX was a 
(A)

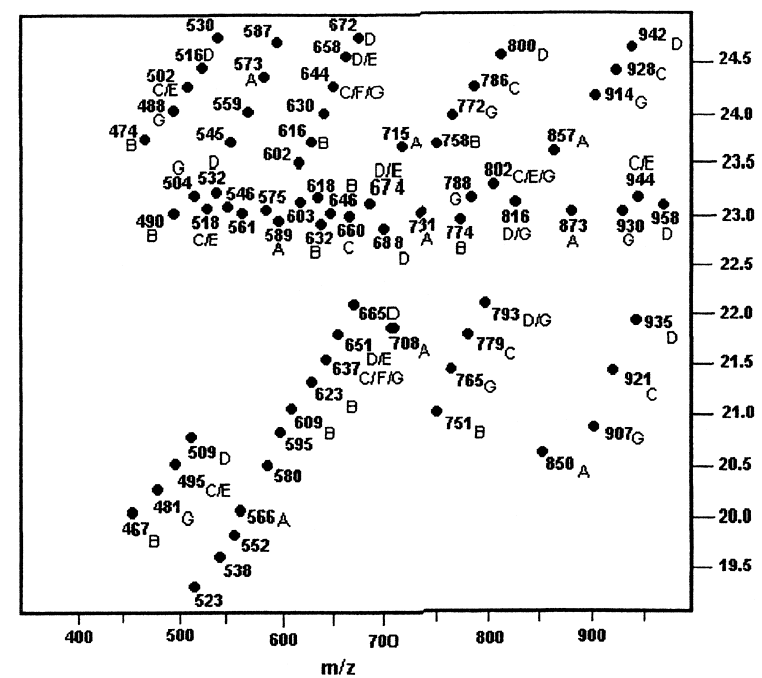

(B)

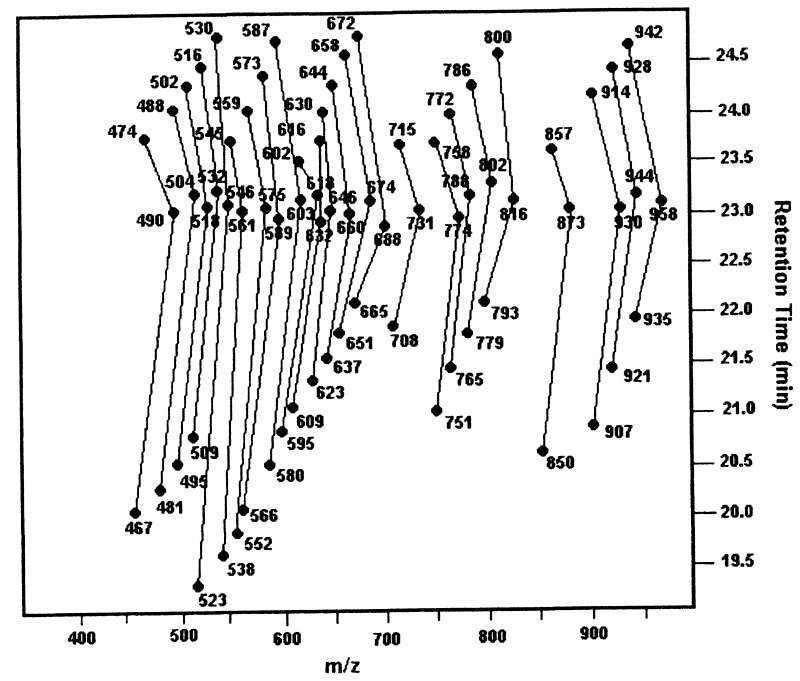

Fig. 1. Schematic representation of the overlapping of all the 2D mass chromatograms from the low molecular mass fractions of the Nephilinae spider venoms. The black spots were placed corresponding to on the retention time of all eluting peaks, obtained by using a RP-microcolumn Develosil ODS-HG-5 $(0.3 \times 150 \mathrm{~mm})$ coupled to HPLC under gradient of MeCN from $0 \%$ to $80 \%$ in $20 \mathrm{~min}$. The numbers represent the molecular masses of the toxins in the monoprotonated form (A). The same mass chromatogram as shown in (A) connected by continuous lines represent a group of toxins sharing exactly the same polyamine backbone and tail (B).

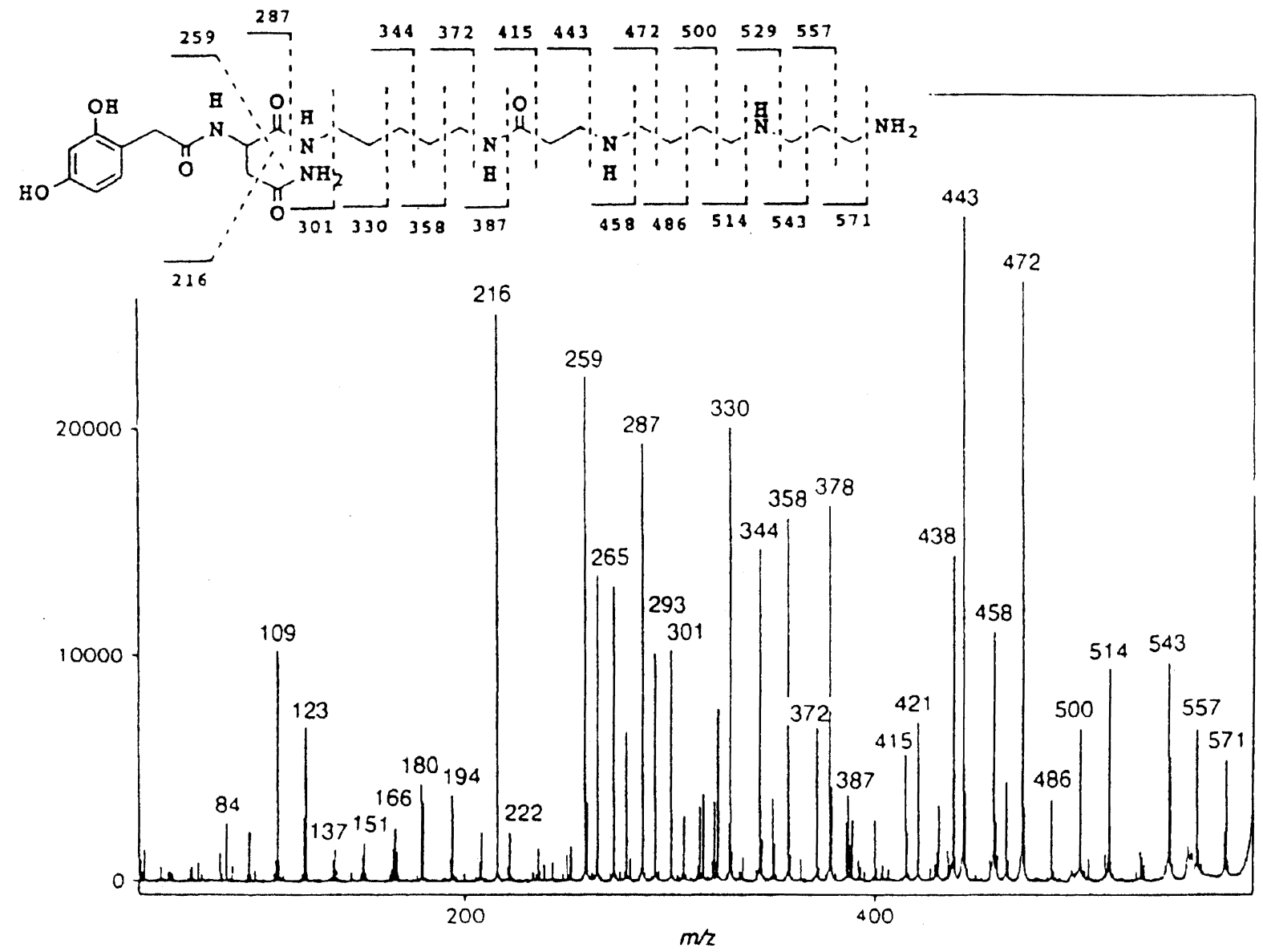

Fig. 2. High energy CID spectrum of sodiated molecular spectrum of JSTX-3 $(\mathrm{M}+\mathrm{Na})^{+} \mathrm{m} / \mathrm{z} 588$ and the fragmentation scheme for JSTX-3. All of product ions appear as the sodium adduct. 
low molecular weight substance and thought to be a peptide. We investigated the venom of the similar orb-weaver spider, Nephila maculata collected in Papua New Guinea. The toxic principle showed the same physiological activity as JSTX and named this toxin NSTX. ${ }^{2}$ 2D ${ }^{1} \mathrm{H}-\mathrm{NMR}$ data of JSTX and NSTX suggested that these toxins were not of the peptide nature. The characterization of JSTX, as well as that of NSTX was performed by means of NMR spectrometry. And we found that the toxins were composed of a variety of closely related compounds with a unique structure containing a 2,4-dihydroxyphenylacetyl or indorylacetyl groups in connection with polyamines through asparaginyl moiety. ${ }^{3), 4)}$ Postsynaptically-acting toxins similar to JSTX or NSTX have subsequently been found in Araneid spiders.5),6)

Recent advance in highly sensitive mass spectrometric techniques has been applied to identify many such polyamine toxins from the other spider venoms. As shown in Fig. $1 \mathrm{~A}$, schematic display of two-dimentional mass chromatogram of the Nephilid venom extract by on-line micro-column HPLC/FABMS, indicated that the venom was composed of more than 70 kinds of components. Each component showed the retention time of the toxic components, and the number corresponding to the each spot represented the molecular mass of each toxin. This means that the conventional analytical techniques would be hard to characterize the features of the whole venom components. Figure $1 \mathrm{~B}$ also indicated that some systematic order was observed in the chromatogram, in which, the patterns consisted of the pairs of three components with the mass difference of 7,16 , and 23 , respectively.

Perfect assignment of the mass fragment of polyamine toxins was performed employing tandem MS/MS with high energy CID charge remote fragmentation technique. For example, spectrum of JSTX-3 was fully characterized as shown in Fig. 2. ${ }^{7}$ As the result of these mass fragment analysis, the mass difference in the Fig. $1 \mathrm{~B}$ corresponded the mass differences of the acyl moiety, i.e., product ion spectra of $(\mathrm{M}+\mathrm{H})^{+}$of 2,4-dihydroxy phenylacetyl (m/z; $123)$, indolylacetyl (m/z; 130) and 4-hydroxy indolyl acetyl $(\mathrm{m} / \mathrm{z} ; 146)$ groups respectively ${ }^{8)}$ (Fig. 3). In addition, respective pairs as shown in Fig. $1 \mathrm{~B}$ indicated that the polyamine part shared exactly the same polyamine backbone and tail. Accordingly CID mass fragment patterns were superimposed with 7 ,

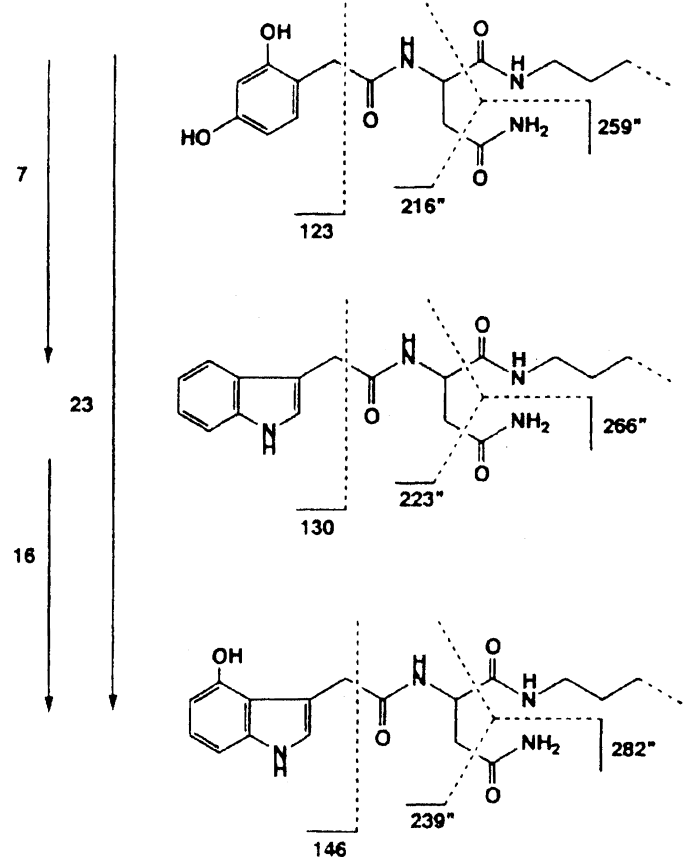

(1)

(2)

Fig. 3. Molecular mass differences of three types of acyl moieties between 2,4-dihydroxy phenyl-, indoryl- and 4-hydroxy indoryl-groups.

16 or 23 dalton shift and these completely mirrored by another (Fig. 4).

Common features of polyamine toxins in the Nephilid spiders. The structural and the pharmacological features of these toxins are quite unique compared to the other arthropod neurotoxins and these compounds are refered to as polyamine toxins. Polyamine toxins were reported from the spider venom only, except philanthotoxin which was from the solitary wasp, Philanthus trianglum. ${ }^{9), 10)}$ During the investigation of the toxic principles, these Nephirid spiders were shown to possess many kinds of the closely related compounds in the venom.

Every polyamine pattern was characterized completely in the venoms of the genera Nephila and Nephilengys. These genera, different from the Araneid spiders having the other polyamine toxins, possess putreanine moiety in the tail of the polyamine part specifically. And in many cases there are putreanine moieties that are doubled or tripled in the tail portion of the toxins. The polyamine toxins from these spiders are classified into 6 types from type A to type F. These toxins were illustrated in Fig. 5. Interestingly, putreanine was first reported as an unusual amino acid in the mammalian brain. ${ }^{11)}$ 


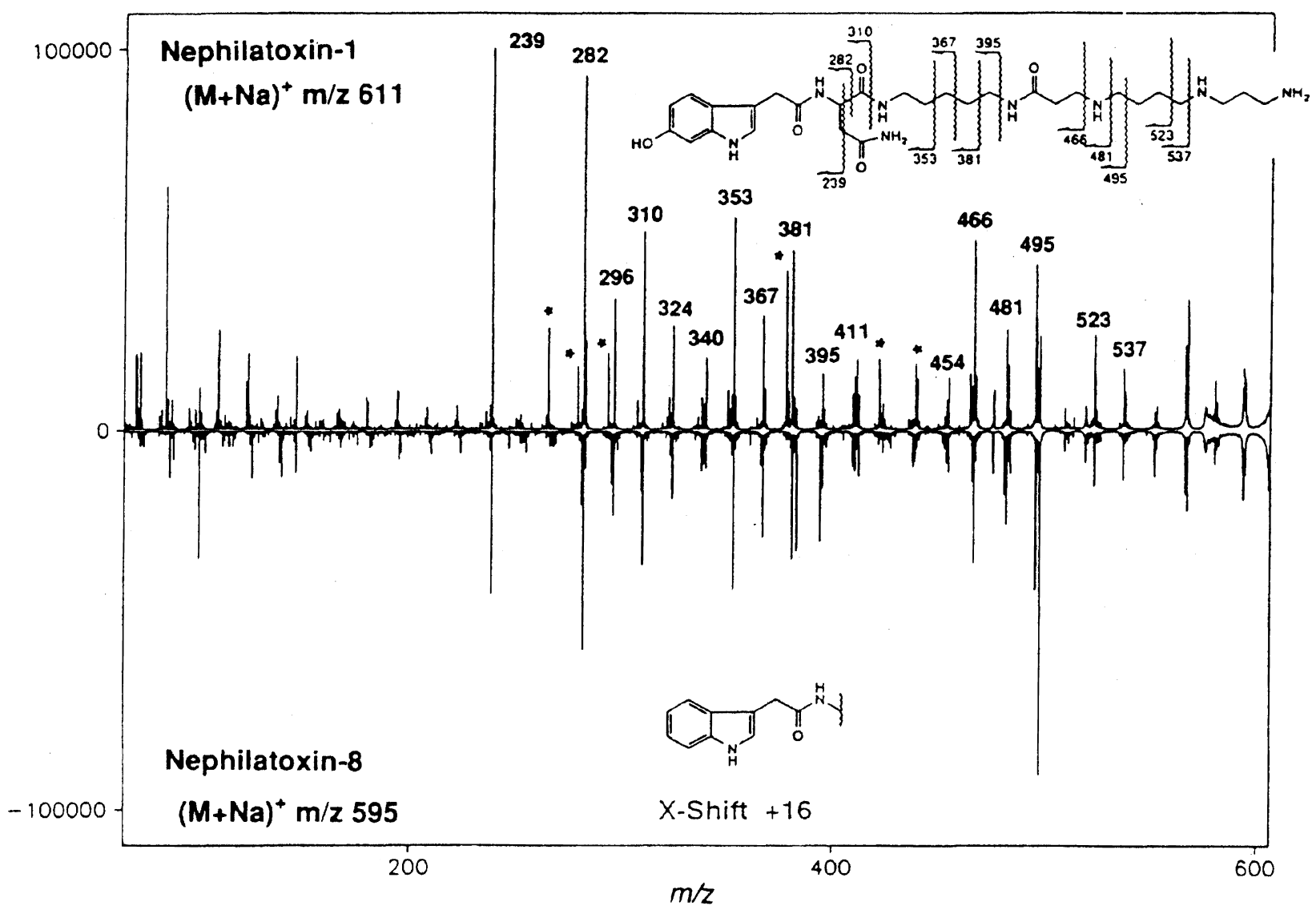

Fig. 4. Comparison with product ion spectra of +16 mass number shifted nephilatoxin- $8(\mathrm{M}+\mathrm{Na})^{+} \mathrm{m} / \mathrm{z} 595$ and that of nephilatoxin-1 $(\mathrm{M}+\mathrm{Na})^{+} \mathrm{m} / \mathrm{z} 611$.

Novel polyamine toxins in the primitive spiders. Spiders are divided taxonomically into two large groups. One is the so-called true spiders belonging to the evolved larger group, Araneomorphae. Nephila and Nephilengys belong to this group. The jaws of this group of spiders are attached below the head and open sideways. The others are thought to be evolutionally primitive, and these include trapdoor spiders, wandering spiders like tarantula, or funnel-web spiders. Their jaws are attached in front of the head, move up and down, opening parallel to long axis of the body. Generally speaking, these primitive spiders possess characteristically one species of polyamine toxin and many kinds of cystine knot rich peptide neurotoxins in the venom. In Iriomote Island, a dangerous primitive spider, Macrothele gigas, possessing lethal venom is a forest inhabitant. This spider is a kind of funnel-web spider. We have investigated the venom of Macrothele gigas by finger printing profile analysis by MALDI-
TOF/MS. ${ }^{12)}$ Novel polyamine toxin was called MG30 (Fig. 6). MG30 is a major toxic component in the venom of Macrothele gigas. The structure of MG30 was deduced by investigation using NMR spectrometry and ESI-Q-TOF MS/MS. Different from the polyamine toxins of Nephilid spiders, bulky acyl part is indolyllactic acid connected with a single chain polyamine. And in addition, protons of secondary amino group of the usual polyamine part are replaced by tertiary dimethyl ammonium moieties. Absolute configuration of the indolyllactyl part was assigned as S-configulation by enantio-selective synthesis. ${ }^{13)}$

Mass spectrometric analysis of linear peptide neurotoxins, a modifier of cellular signal transduction. After that the finding of the mast cell degranulating peptide, mastoparan, in the wasp venom, ${ }^{14)}$ similar types of such linear amphiphilic peptides have been characterized from the other wasp venoms. ${ }^{15)}$ These peptides take characteristically amphiphilic alfa-helical structures in hydropho- 


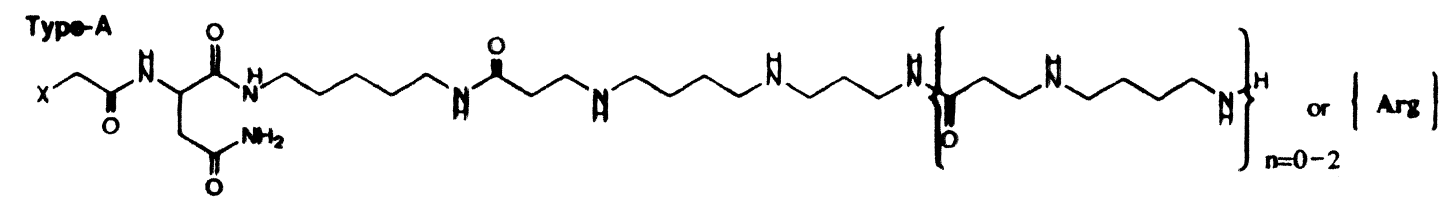

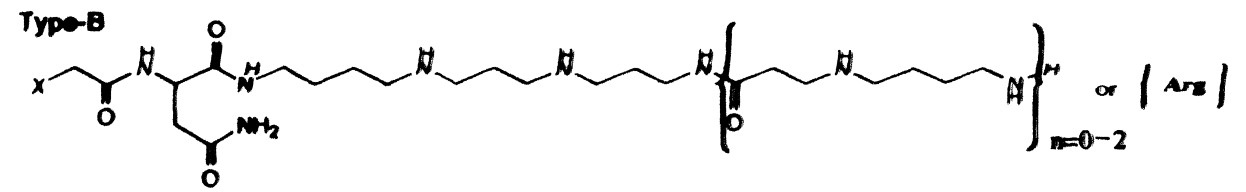

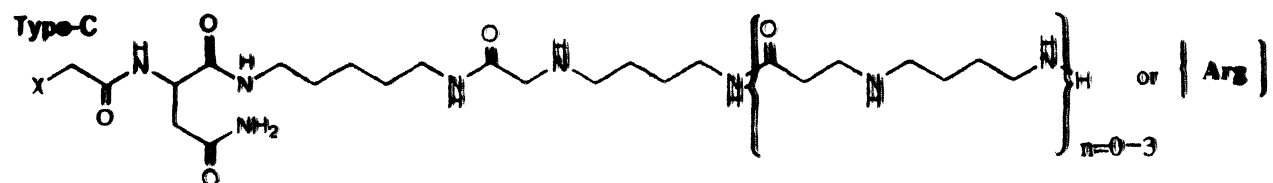

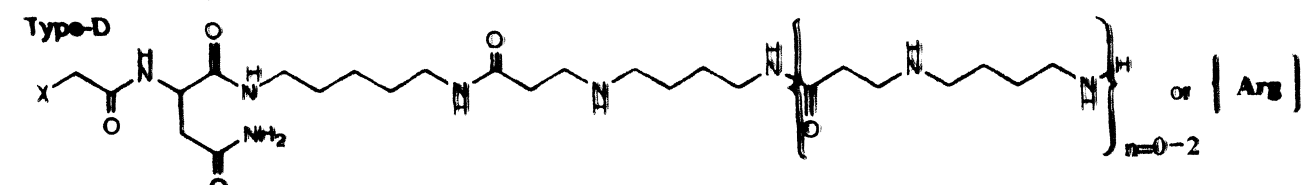

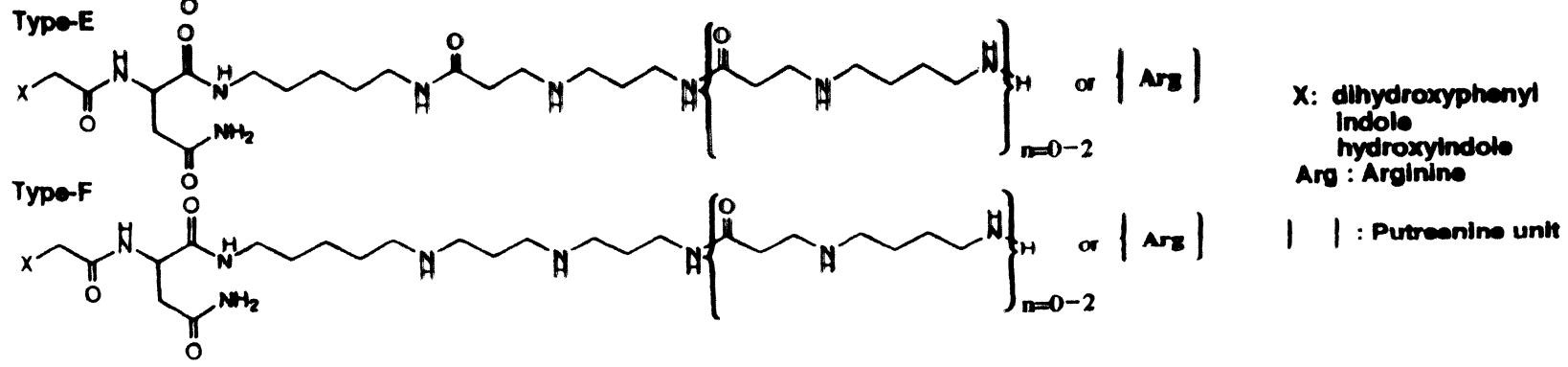

Fig. 5. Generalized structure of currently identified spider polyamine toxins obtained from the genera Nephila and Nephilengys.<smiles>C[N+](C)(CCCN)CCCC[N+](C)(C)CCCCNC(=O)[C@@H](O)Cc1c[nH]c2ccccc12</smiles>

Fig. 6. Novel structure of polyamine toxin in the venom of primitive spider, Macrothele gigas from Iriomote Islands.

bic circumstances such as in the cell membrane, and exert versatile biological actions based on their amphiphilicity. Multi-talented traits include, for instance, the release of insulin from the pancreatic $\mathrm{B}$ cells, and catecholamines from the adrenal chromaffin cells etc. ${ }^{16)}$ These interesting activities in the granular cells are due to the direct activation of the peptide on the GTP-binding protein (Gi, Go) in the cells. ${ }^{17)}$

In higher concentration, the peptide makes a cluster and interacts on a lipid bilayer as a poreforming peptide, which causes haemolytic action, cell-lysis, and bacteriocidal activities or enhances the toxic activity of the other co-existing venomous principles as the spreading factor. ${ }^{18)}$

The presence of this kind of amphiphilic peptides have recently been recognized apart from the other arthropod venoms. For the investigation of such new class of linear peptides from the arthropod venoms, we have established rapid and micro-analytical methodology utilizing various kinds of mass spectrometry. A method incorporating nested collision-induced dissociation/post-source decay (CID/PSD) was examined by combination with the ladder sequence analysis of MALDI-TOF after partial digestion of the peptide by exopeptidase. ${ }^{19)}$

General strategy of mass spectrometric sequencing was as follows: After the chromatographic separation of the venomous component was obtained from one venom sac, $1 / 50$ to $1 / 100$ of the chromatographic peak was digested by exopeptidases such as carboxypeptidase (CPY) or aminopeptidase (APM), and the respective digested mixture was measured by ladder sequencing technique of MALDI-TOF MS. In 


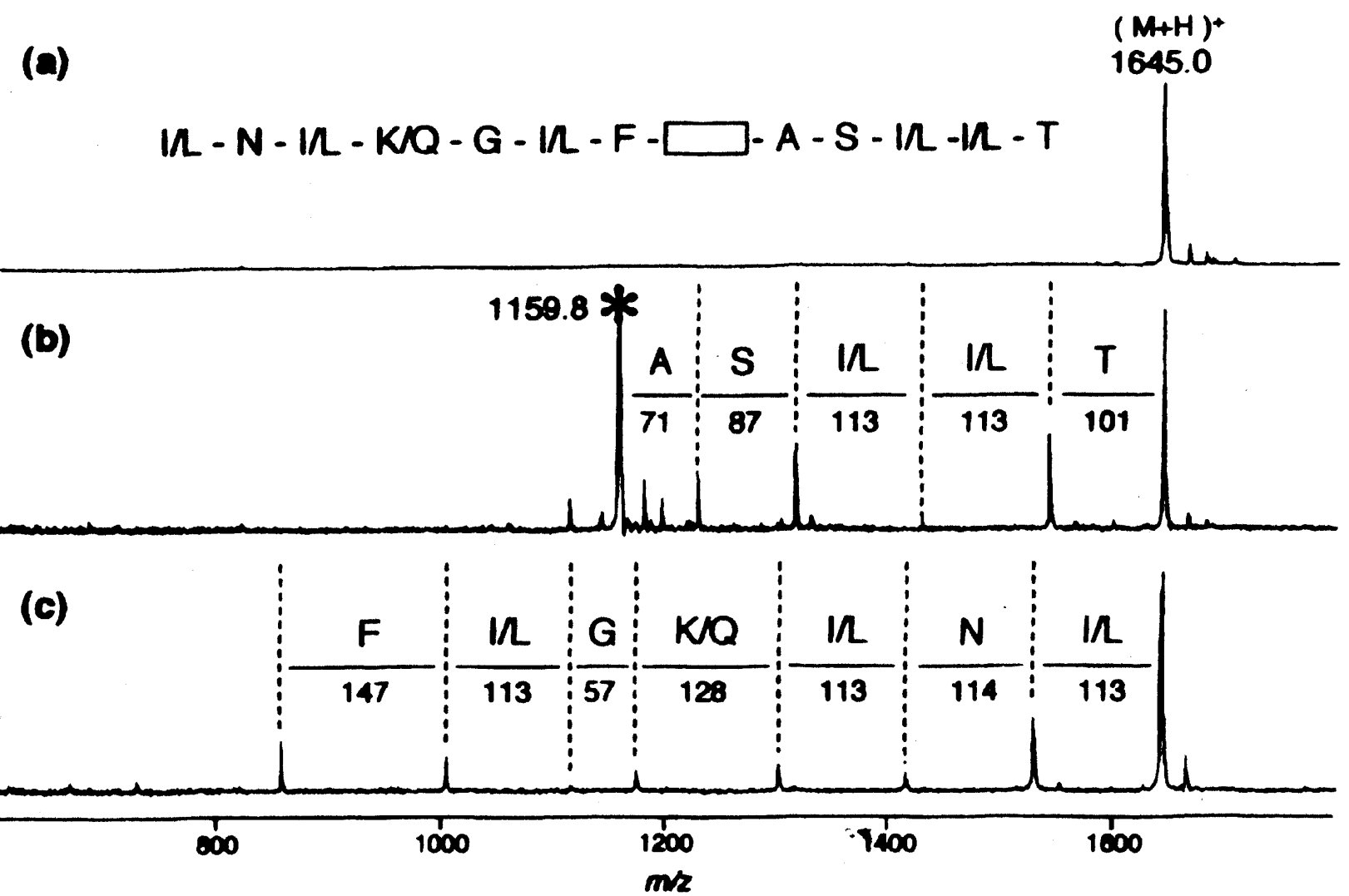

Fig. 7. Ladder sequencing of a linear peptide from the solitary wasp, Eumenes rubronatatus. (a) MALDI spectra of intact peptide, (b) carboxypeptidase $\mathrm{Y}$ digest, (c) aminopeptidase $\mathrm{M}$ digest. Peak marked $(*)\left([\mathrm{M}+\mathrm{H}]^{+}\right.$at $\left.\mathrm{m} / \mathrm{z} 1159.8\right)$ was analyzed by CID/PSD (see Fig. 8 a). Unidentified residues indicated by rectangle.

the case of N-terminal modified peptide such as pyroglutamic acid, combination of pyrrolidone carboxyl peptidase and APM was employed. ${ }^{20)}$ The middle part of the peptide sequence which was observed only in the CID/PSD spectrum of a ladder peptide, was extracted as C-terminal fragment ions. Assignment of C-terminal fragment ions enabled calculation of N-terminal fragment masses, leading to differentiation between N-terminal fragment ions and internal fragment ions.

Distinction between glutamine and lysine residue on the sequence was performed by acetylation of the peptide prior to the mass analysis, since the lysine residue was shifted 42 mass unit with acetyl moiety. The leucyl and isoleucyl residues were distinguished by the presence of $w$-ion for leucine and $d$-ion for isoleucine derived from the side chain fragments in CID mass spectrogram. This methodology allowed rapid and sensitive identification by removing ambiguity in the assignment of the fragment ions, and proved useful for sequencing unknown peptides.
A typical example of the analyzing data from the venom of the solitary wasp, Eumenes rubronatatus, was illustrated in Fig. 7 and Fig. 8.

Figure 7 illustrates the MALDI-TOF ladder sequence of the insufficient digestion of the peptide by exopeptidases. The insufficient digestion contains the mixture of digested peptides with the ladder indicating the molecular mass of each peptide. Accordingly, the difference of these molecular masses corresponds to be composed amino acid from the termini. Subsequently, Fig. 8 shows the parallel displays of the nested CID/PSD spectra of ladder peptide and intact peptide. By comparison with the CID/PSD spectra obtained from the C-terminal deficient peptide as the precursor and that of the native intact peptide, assignment of C-terminal fragment ions enables calculation of $\mathrm{N}$-ternimal fragment masses, leading to differentiation between N-terminal fragment ions and internal fragment ions. Since both native peptide and $\mathrm{C}$-ternimal deficient ladder peptide include identical $\mathrm{N}$-terminal amino acid sequences, 


$$
L-N-L-K-G-I-F-K-K-V-A-S-L-L-T
$$

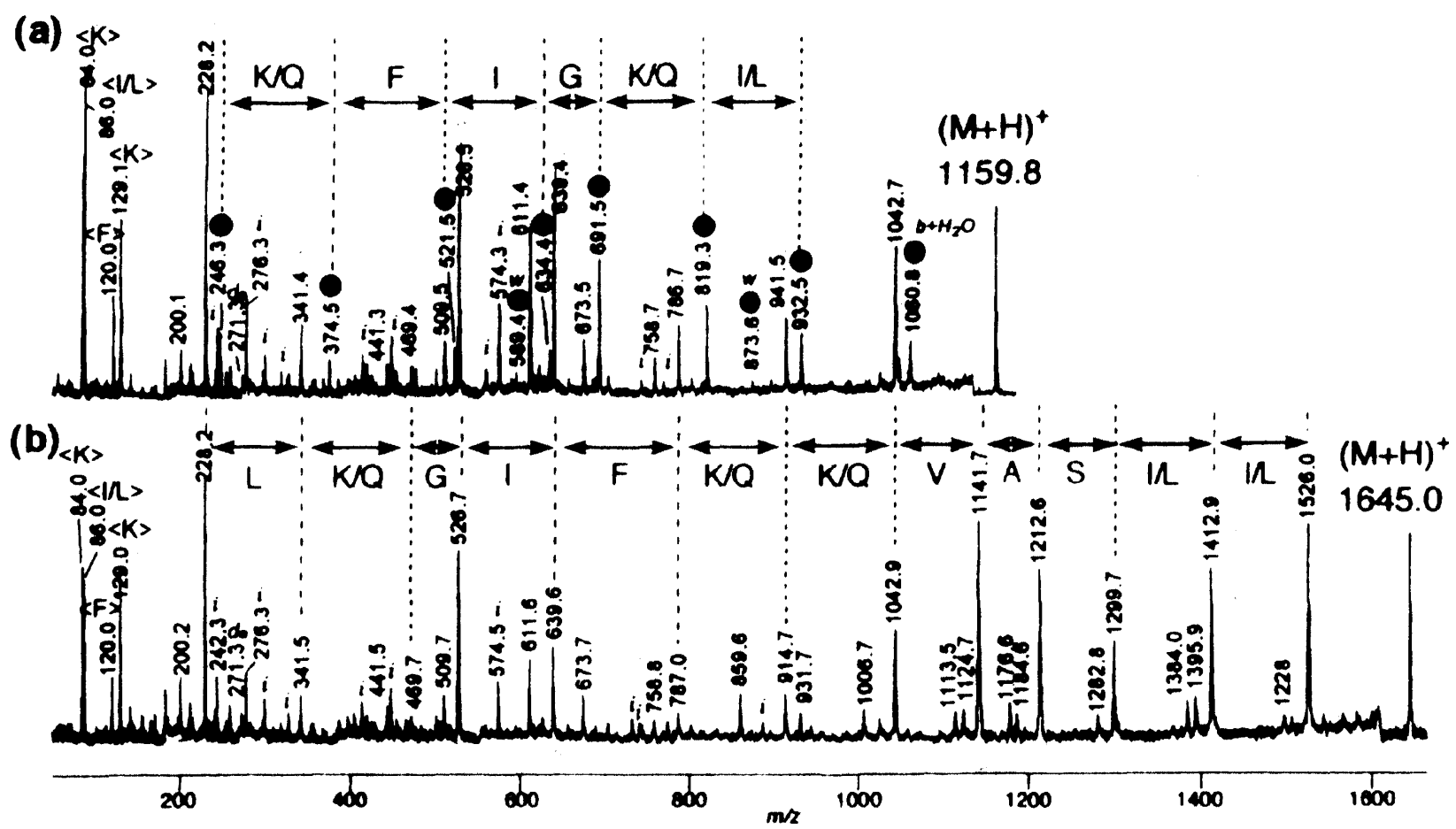

Fig. 8. Nested CID/PSD spectra of solitary wasp peptide in Fig. 7. (a) CID/PSD spectra of ladder peptide derived from carboxypeptidase $\mathrm{Y}$ digest and (b) intact peptide. Ion peaks observed only in (a) are marked $(\bullet)$.

the common mass peaks in the CID/PSD spectra of these two peptides are evidently N-terminal ions, or common internal fragments. Therefore, the mass peaks observed in only one of either the CID/PSD spectrum of intact peptide or that of the ladder product should be derived from the C-terminal sequence unknown. Accordingly, this methodology enables us to sequence unknown peptide toxins, in particular those available as natural products with a limited supply.

In this way, amphiphilic linear peptides in the venoms of solitary wasp, ${ }^{19)-22)}$ spiders ${ }^{23)}$ and scorpions $^{18), 24)}$ were characterized and shown in Fig. 9.

Cystine knot rich peptide neurotoxins, mass spectrometric determination of cystine bridges. It is well known that the snake neurotoxins contain comparatively high rates of cystine residues in a molecule. The other neurotoxins in scorpions and various types of conus toxins, which affect the neuronal transmission are also recognized rich in such cystine knots in the toxin molecules. ${ }^{25}$ ) The cysteine contents of these neurotoxins are more than $20 \%$ and this fact suggests that the structure of such neurotoxin is tightly fixed by trussing up of many cystine bridges in a molecule.

In 1990, a new neurotoxin was found in the venom of funnel weaver spider, Agelena opulenta (Agelenidae). This toxin blocks the neuronal transmission at the lobster leg neuro-muscular synapses presynaptically. The toxin is cystine-knot rich in peptide and was named agelenin. ${ }^{26)}$ The electrophysiological studies suggested that agelenin is effective only for arthropod neurotransmission specifically and acts as a blocker of calcium ion channel in the plugging mode. This type of arthropod selective toxin is now called insect toxin (IT).

The conventional analysis using cystine oxidation, enzymatic digestion followed by Edman degradation was achieved and primary amino acid sequence deduced. ${ }^{26)}$

Agelenin contains 6 cysteine residues in a molecule (Fig. 10). Among three cystine bridges, $\mathrm{Cys}_{10}{ }^{-} \mathrm{Cys}_{24}$ was easily decided, because the $\mathrm{Cys}_{10^{-}}$ $\mathrm{Cys}_{24}$ containing peptide fragments were easily iso- 


\title{
SOLITARY WASP \\ Anterhynchium flavimarginatum \\ INLLKIAKGIIKSL-NH2 \\ Eumenes micado \\ LKLMGIVKKVLGAL-NH2 \\ FDIGIILKKVVSGL-NH2 \\ Eumenes rubronotatum \\ LNLKGIFKKVASLLT-OH \\ Batozonellus macrifrons \\ RIKIGLFDQLSRL-NH2 \\ RIKIGLFDQLSKL-NH2 \\ ZTAPVPKAISK-NH2 \\ SIPAMLKRMRK-NH2 \\ Anoplius samariensis \\ RIKIGLFDQLSKL-NH2 \\ GLKRIKTLL-NH2 \\ ZDPPVVKMK-NH2
}

\author{
PARAPONERA ANT \\ Paraponera clavata \\ FLPLLILGSLLMTPPVIQAIHDAQR-NH2 \\ SPIDER \\ Oxyopes kitabonsis \\ GKSFVFGKILRSIAKVFKGVGKVRKQFKTASDLDKNQ-OH \\ FRGLAKLLKIGLKSFARVLKKVLPKAAKAGKALAKSMADENAIRQQNQ-OH \\ SCORPION \\ Pandinus imperator \\ GKVWDWIKSAAKKIWSSEPVSQLKGQVLNAAKNYVAEKIGATPT-OH \\ FWGALAKGALKLPSLFSSFSKKD-OH \\ Opisthacanthus madagascarionsis \\ IFGKIWEGIKSLF-NH2 \\ IFGAIWNGIKSLF-NH2
}

Fig. 9. Illustration of amphiphilic linear peptides in the venom of arthropod.

\section{$\mathrm{GGC}_{3} \mathrm{LPHNRF}_{10} \mathrm{NALSGPRC}_{18} \mathrm{C}_{19} \mathrm{SGLKC}_{24} \mathrm{KELSIWDSR}_{34 \mathrm{~L}-\mathrm{NH}_{2}}$ agelenin \\ GC $_{2}$ LGEGEKC ${ }_{9}$ ADWSGPSC ${ }_{17} \mathrm{C}_{18}$ DGFYC $_{23} \mathrm{SC}_{25} \mathrm{RSMPYC}_{31} \mathrm{RC}_{33} \mathrm{RNNS} \mathrm{NH}_{2}$ $\delta$-palutoxin}

Fig. 10. Amino acid sequences of agelenin and $\delta$-palutoxin.

lated after trypsin digestion of agelenin. However, it was hard to decipher the other bridging mode of cystine knot between $\mathrm{Cys}_{3}-\left(\mathrm{Cys}_{18}, \mathrm{Cys}_{19}\right)-\mathrm{Cys}_{34}$, since $\mathrm{Cys}_{18}$ and $\mathrm{Cys}_{19}$ are located in the adjacent position. Therefore, the precise structure of agelenin was determined by chemical synthesis, in which, two kinds of cystine knot structures, i.e., combinations of $\left[\mathrm{Cys}_{3}-\mathrm{Cys}_{18}, \mathrm{Cys}_{19}-\mathrm{Cys}_{34}\right]$ and $\left[\mathrm{Cys}_{3}-\mathrm{Cys}_{19}, \mathrm{Cys}_{18}-\right.$ $\left.\mathrm{Cys}_{34}\right]$ were synthesized individually and their chromatographical features were compared to those of natural toxins. ${ }^{27)}$ From these experiences, we have established the more rapid and conventional methodology for deciding the mode of cystine-knot employing various kinds of mass spectrometry. For instance, a cystine knot containing tryptic fragment, $\mathrm{Cys}_{3}-$ $\left(\mathrm{Cys}_{18}, \mathrm{Cys}_{19}\right)-\mathrm{Cys}_{34}$, was treated by Edman procedure once, and each molecular mass in the reaction mixture was subsequently observed by MALDI-TOF (Fig. 11). The molecular mass of the reaction prod-

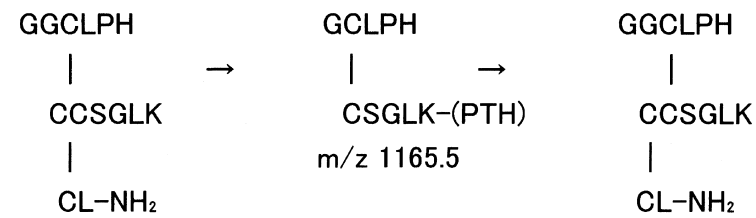

one step Edman degradation estimated cystine bridge

Fig. 11. Rapid cystine-knot analysis containing adjacent Cys-Cys sequence by MALDI-TOF MS. Cystine containing tryptic peptide fragment was treated 1 cycle procedure of Edman degradation. Molecular ion $(\mathrm{m} / \mathrm{z}$ 1165.5) corresponded $\mathrm{C}_{3}-\mathrm{C}_{19}$.

uct was $\mathrm{m} / \mathrm{z}$ 1165.5. This observation suggested that the cystine knot was bridged in the positions of $\mathrm{Cys}_{3}-$ $\mathrm{Cys}_{19}$ and $\mathrm{Cys}_{18}-\mathrm{Cys}_{34}$ respectively.

Another cysteine rich insecticidal neurotoxin, $\delta$-palutoxin IT, was isolated from the venom of the similar funnel weaver spider, Paracoelotes luctousus (Amaurobiidae). ${ }^{28}$ ) Different from agelenin, $\delta$-palutoxin IT contains 8 cysteine residues (Fig. 10), and acts on the sodium channel of the insects. $\delta$ Palutoxin disturbs closing of the once opened sodium channels. ${ }^{28)}$ The sequence analysis of $\delta$-palutoxin was also achieved by monitoring the MALDI-TOF mass spectrometric features after partial reduction of the cystine bridges. The peptide was partially reduced by tris-(2-carboxyethyl)-phosphine, then, 
cyanylated with 1-cyano-4-dimethylaminopiridinium tetrahydroborate, followed by usual proteolytic cleavage of the treated peptides as reported previously $^{29)}$ (Fig. 12).

General mode of cystine knots in the arthropod neurotoxins. An approach employing the mass spectrometric analysis for the detection of the mode of the cystine bridges is quite effective and various kinds of cystine rich peptide neurotoxins were characterized by using a combination of chemical procedures and mass spectrometric techniques.

As a result of these chemical investigations, the major mode of cystine knots in the neurotoxins of the spiders and scorpions are briefly wrapped up into two types as illustrated in Fig. 13.

The peptides belonging to group A in Fig. 13, possess 3 or 4 cystine bridges and characteristically contain adjacent 2 cystein residues in the middle of the peptide. The peptides belonging to group B also

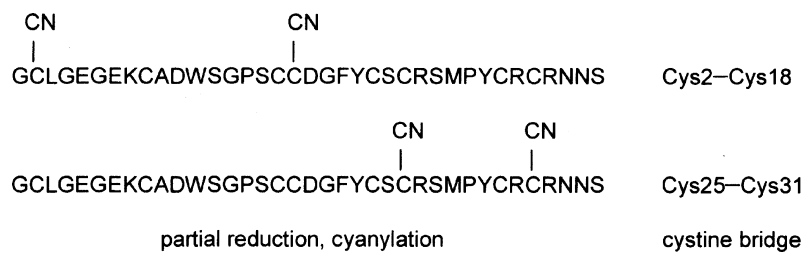

Fig. 12. Determination of disulfide bridges of the toxin of spider, Paracoelotes luctousus. The partially cyanylated residues are indicated by $\mathrm{CN}$. These 2 isomers were respectively digested by trypsin followed by chymotrypsin. Each of the chymotryptic peptides were analysed for their molecular masses and sequences.

\section{Group A

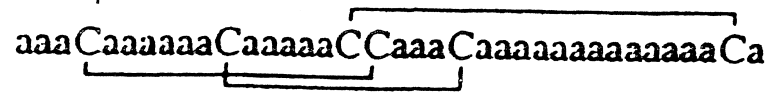

agelenin(spider)

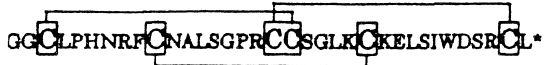

maurocalcin(scorpion)

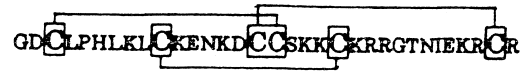

$\mu$-agatoxin(spider)

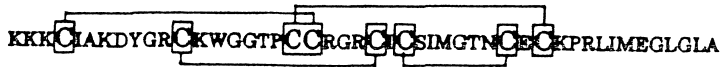

possess 3 or 4 cystine bridges and the locations of the cystine bridges are distributed rather uniformly. In addition, the difference of the peptides in groups A and B appears in their solution structures as described later.

The group A peptides are widely distributed in the spider including trap door spiders (Aptosticus $),{ }^{30)}$ funnel-web spiders (Hadronyche), ${ }^{31)}$ tarantulas (Brachypelma, Gramstola $)^{32)}{ }^{33)}$ etc. These types of neurotoxins mostly affect various kinds of calcium channels, ${ }^{33)}$ while the toxins isolated from the tarantula venoms were reported to acts on Kv2 and Kv4 potassium channels. ${ }^{34}$ ) Most of the toxins in group A are reported predominantly in the spider venoms. Besides spider venoms, only two species of scorpions (Scorpio, Pandanus) ${ }^{35)}$, 36) possess this type toxin. Interestingly, we have found that assassin bugs (Hemiptera, Reduviidae) contain this type of neurotoxin as the paralytic weapon in their salivary glands. ${ }^{37)}$ And in some leaf beetles (Coleoptera, Gastrophysa), similar peptide possessing the same mode of cystine knot is utilized as a diapause inducing tool, ${ }^{38)}$ which might act as an endogenous neurotransmitter blocker in the hibernating insect. The peptides belonging to the group A are also distributed in conus shell venoms.

The peptides also belonging to group A with 4 cystine knots are reported elsewhere. The 4th cystine bridge is located between 5 th and 6th cysteine residues in the 3 cystine knots group. This type of peptide is widely distributed in the spider venom,

\section{Group B}

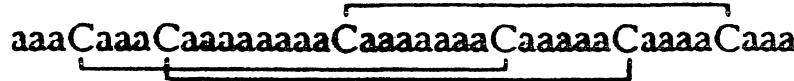

ESTX(tarantula)

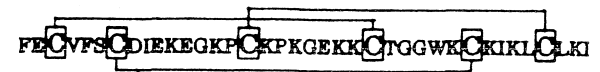

PO1(scorpion)

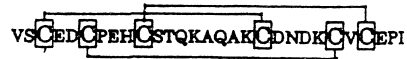

HsTX(scorpion)

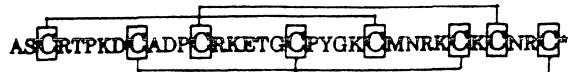

Fig. 13. A typical, generalized mode of cystine knots in arthropod neurotoxins. 


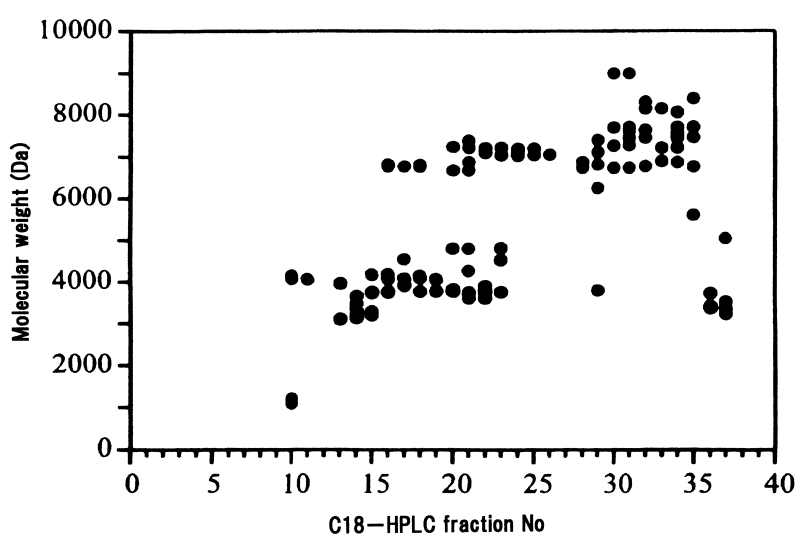

Fig. 14. Schematic displays of the whole venom components of the Chinese scorpion, Buthus martensi, by HPLC-mass chromatography.

but is not yet found in the scorpions, insects or conus shells. Some of these peptides also block calcium ion channels, but the major part of the peptides blocks sodium channel. ${ }^{28), 29)}$

The peptides belonging to the group B are mostly reported from the scorpion venoms. These types of peptides are known to block various kinds of potassium channels. For example, the venom of Chinese scorpion, Buthus martensi possesses more than 10 kinds of such peptides. Figure 14 illustrates the schematic display of the mass chromatogram of Chinese scorpion Buthus martensi. ${ }^{39)}$

The peptides with the approximate molecular weight between $6000-7000$ are the sodium channel blockers usually observed in the other scorpions and the peptides around molecular weight 3000-4000 are the various types of potassium channel blockers involving usual voltage gated potassium channels, big or small conductance calcium sensitive potassium channels. ${ }^{39)}{ }^{40)}$ The amino acid sequences of the major potassium channel blockers in the venom of scorpion, Buthus martensi are shown in Fig. 15. In spiders, this type of peptide is known only the tarantula belonging to the genus Brachypelma.

The four cystine-bridged scorpion toxins that are closely related to the usual group B toxins have been found in the venoms of the minor families of the tropical scorpions, Heterometrus spinifer ${ }^{40)}$ and Opisthacanthus madagascariensis respectively. ${ }^{41)}$

As predicted from the data of NMR spectrometry, the solution structures of the group A peptides in Fig. 13, suggest that a pair of anti-parallel $\beta$-sheets and disordered peptide chains are fixed by 3 or 4
Kv(voltage gated potassium channel)

BmKTX GINVKCKHSGOCLKPCKDA-GMRFGKCINGKCDDCTPK

Kv, BKCa (big conductance Ca sensitive potassium channel)

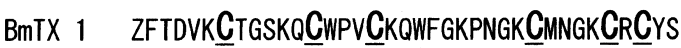

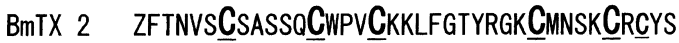

BmTX 3 ZVETNVKCGGGS-

SKCa (small conductance $\mathrm{Ca}$ sensitive potassium channe I)

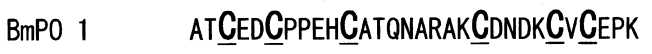

BmPO 2 AGEEE $\underline{C}$ PM-HCKGKNAKPTCDDGV $\underline{C} \underline{C}$ NV

BMPO 3 VGEEE-

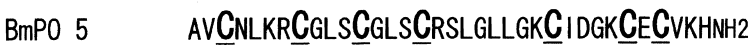

Fig. 15. Some examples of potassium channel blockers in the venom of Buthus martensi.

cystine knots (Fig. 16 A ${ }^{42)}$ and the anti-parallel $\beta$ sheets is likely to interact on the outside surface of the ion channels.

The solution structures of the peptides in group B neurotoxins are different from those of group A peptides. The structure is composed of pairs of 2 or 3 anti-parallel $\beta$-sheets which are similar to the group A peptides, but different from the group A peptides, anti-parallel $\beta$-sheets are hanged by cystine knots from the $\alpha$-helical peptide chain (Fig. 16 B). ${ }^{43)-46)}$

Recently, similar cystine knot peptide was found in solitary wasp. Since Fabre's description, the longlasting non-lethal paralytic activity in the solitary wasp venom has never been characterized chemically. We have identified the novel cystine knot rich neurotoxin from the venom of solitary wasp, Anoplius samariensis. ${ }^{47)}$ The wasp, Anoplius samariensis, preys spiders.

The venom contains $\gamma$-amino butyric acid, glutamic acid and small molecular weight peptides, however, these low molecular weight components did not show such long-lasting paralytic activity for the target spider, Nephila clavata. The venom contains various high molecular weight proteins and the high molecular weight fraction was responsible for the paralytic activity. The primary structure of one component designated as shown in Fig. 17, As-fr-19. The protein, As-fr-19 was a novel multiple cysteine rich peptide with high sequence similarity to snake toxins including dendrotoxins (dendrotoxin $\mathrm{K},{ }^{48}$ ) dendrotoxin $\mathrm{I}^{49}$ ), calcludine ${ }^{50}$ ) and several sea anemone 
A anti-parallel $\beta$-sheet

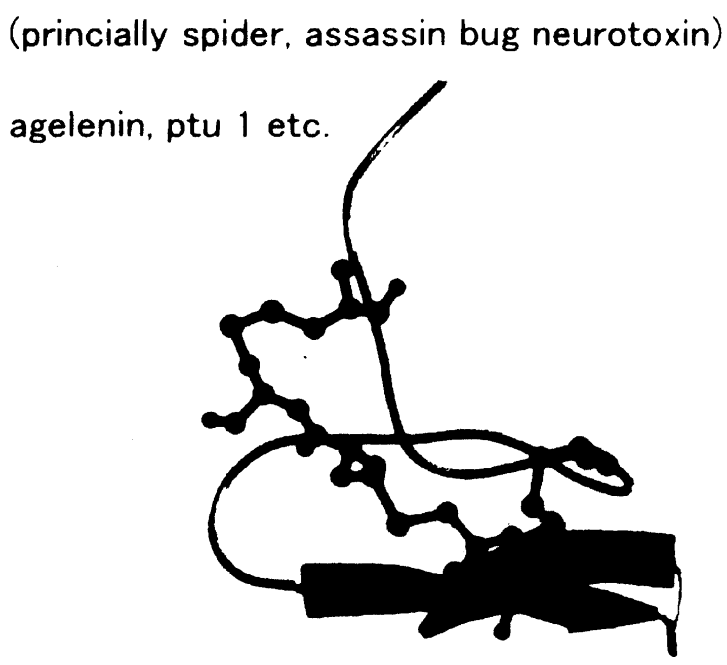

$B$ anti-parallel $\beta$-sheet $+\alpha$-helice

(principally scorpion neurotoxin)

BmP05, HsTX etc.

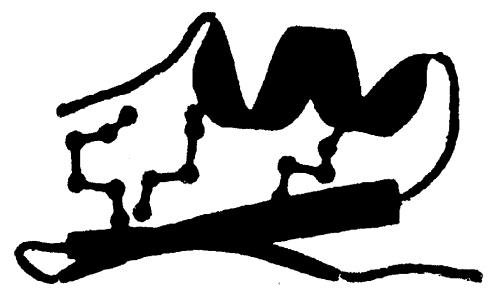

Fig. 16. Ribbon diagram of the backbone peptide folding of the group A and B peptide in Fig. 13.

toxins. ${ }^{51)}$ Interestingly, the localization of the cystine knots of these peptides are homologous to aprotinin, the pancreatic Kunits type of trypsin inhibitor. ${ }^{52)}$

Novel cystine knot neurotoxins. Among the most often illustrated arthropod neurotoxins, the numbers of cystine knots are 3 or 4 . In contrast to such cystine rich neurotoxins, a few neurotoxins in the bee venom peptides and recently reported scorpion peptides, possess only two cystine knots. Bee venom neurotoxins have been characterized from the early 1960s by E. Habermann et al. ${ }^{53)}$ The bee venom contains such cystine containing peptides was named apamin, mast cell degranulating (MCD) peptide, and two other cystine knots small peptides homologous to apamin, in the venom. ${ }^{54}$ Apamin is a powerful neurotoxin and serves as the blocker of small conductance calcium sensitive potassium channel. ${ }^{55)} \mathrm{MCD}$ peptide plays a role in the release of histamine from mast cells. MCD peptide has recently been recognized as neurotoxin, which inhibits voltage dependent potassium channels (Kv. 1.1, Kv. 1.2) selectively. ${ }^{56)}$

These neurotoxins are the smallest type within the arthropod neurotoxins, consisting of around 20 amino acid residues with two cystine knots. Regarding the mode of cystine knots in all of these bee venom peptides, 4 cysteine residues, $\mathrm{Cys}(1) \sim$ Cys(4), are connected in cross sectional as Cys(1)Cys(3) and Cys(2)-Cys(4) respectively ${ }^{54)}$ (Fig. $\left.18 \mathrm{~A}\right)$.
Dendrotoxin I (African elapid snake)

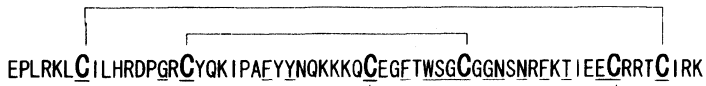

As-fr-19 (solitary wasp toxin)

VSFCLLPIVPGPCTTOYVIRYAFQPSISACRRETFGGCEGNDNNEMTRRDCEHYCEELL

Dendrotoxin $\mathrm{K}$ (black mamba snake) AAKYKLLPLRI GPCKRKIPSEYYKWKAKOCLPEDYSGCGGNANREKI I EECRRTCVG

Calcludine (green mamba snake)

WQPPWYCKEPVRI GSCKKOFSSEY FKWTTAKKCLPFLFSGCGGNANRFOI I GECRKKCLGK

Ask 1 (sea anemone toxin)

INKD CLLPMDVGR CRASHPRYYYYNSSSKR CEKE I YGGCRGNANNFHILEECEKVCGGR

Aprotinin (pancreatic trypsin inhibitor) RPDFCLEPPYTGPCKARI I RYFYNAKAGL COTFVYGGCRAKRNNFKSAEDCMRTCGGA

Fig. 17. Sequence homology of As-fr-19, other related toxins and bovine trypsin inhibitor. Underlined amino acid residues are common or homologous in each peptide sequence.

The newly characterized scorpion neurotoxins, named $\kappa$-hefutoxin ${ }^{57}$ from the venom of Heterometrus fulvipes and Om-toxins ${ }^{58}$ from Opisthacanthus madagascariensis, were recently found from the tropical scorpions belonging to the minor family, Scorpionidae and Ishunuidae. Different from the scorpions belonging to Buthidae, the major family involving many species among the scorpion's world, the venoms of both scorpions belong to minor fam- 


\section{A Bee Venom Type 2 Cystine Knots}

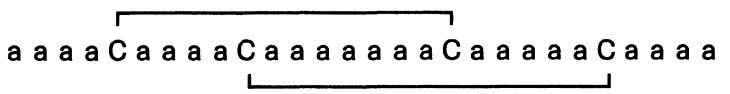

\section{B Scorpion Type 2 Cystine Knots}

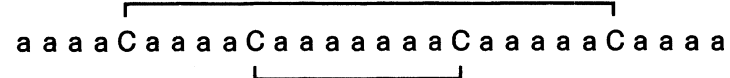

Fig. 18. Comparison of two cystine knot neurotoxins from the bee and scorpion venoms.

ilies, Scorpionidae and Ishnuidae, are not fatal for mammals respectively. These venom peptides are similar in size and the numbers of cysteins to those of the bee venom neurotoxins. However, the mode of cystine knots in these scorpion venom peptides are located in parallel-wise as $\mathrm{Cys}(1)-\mathrm{Cys}(4)$ and $\mathrm{Cys}(2)-$ Cys(3) respectively (Fig. 18 B). The solution structures of these peptides are determined by NMR spectroscopy. ${ }^{58)}$ The peptides have two $\alpha$-helices as helixloop-helix structure which is stabilized by two cystine knots. Electrophysiological experiments demonstrated that Om-toxins decreased the amplitude of $\mathrm{K}^{+}$current of Kv1.1, 1.2 and 1.3. Hefutoxin is also reported as the blocker of voltage dependent potassium channel. ${ }^{57)}$

Acknowledgements. This research was carried out under the enthusiastic and the kindest cooperation of the members in Suntory Institute for Bioorganic Research. I would like to express my hearty gratitude to Drs. Y. Itagaki and H. Naoki for the mass spectrometric analysis of spider polyamine toxins, to Drs. M. Hisada, R. Romi-Lebrun, G. Corzo, L, Dai, T. Iwashita and N. Yamaji for the characterization of many neurotoxins of the venoms in insects, spiders, and scorpions of peptide nature. The author also thank to Drs. H. Darbon and G. Ferrat, CNRS France for the NMR analysis of the solution structures of the toxins.

\section{References}

1) Kawai, N., Niwa, A., and Abe, T. (1982) Brain Res. 247, 169-171.

2) Aramaki, Y., Yasuhara, T., Higashijima, T., Yoshioka, M., Miwa, A., Kawai, N., and Nakajima, T. (1986) Proc. Jpn. Acad., Ser. B 62, 359-362.

3) Aramaki, Y., Yasuhara, T., Higashijima, T.,
Miwa, A., Kawai, N., and Nakajima, T. (1987) Biomed. Res. 8, 167-173.

4) Aramaki, Y., Yasuhara, T., Shimazaki, K., Kawai, N., and Nakajima, T. (1987) Biomed. Res. 8, 241-245.

5) Grishin, E. V., Volkova, T. M., Arsenév, A. S., Reshetova, O. S., Onoprienko, V. V., Magazanik, L. G., Antonov, S. M., and Fedrova, I. M. (1986) Bioorg. Khim. 12, 11-21.

6) Jackson, H., and Usherwood, P. N. R. (1988) Trends Neurosci. 11, 278-283.

7) Eldefrawi, A. T., Eldefrawi, M. E., Konno, K. Mansour, N. A., Nakanishi, K., Oltz, E., and Usherwood, P. N. R. (1988) Proc. Natl. Acad. Sci., USA 85, 4910-4913.

8) Piek, T., Fokkens, R. H., Karst, H., Kruk, C., Lind, A., van Malre, J., Nakajima, T., Nibbering, M. M., Shinozaki, H., Spanjer, W., and Tong, Y. C. (1988) In Neurotox '88: Molecular basis of drug and pesticide action (ed. Lunt, G. G.). Elsevier, Amsterdam, pp. 61-76.

9) Itagaki, Y., and Nakajima, T. (2000) Toxicol.Toxin Rev. 19, 23-52.

10) Fujita, T., Itagaki, Y., Naoki, H., and Nakajima, T. (1995) Rapid Commun. Mass Spectrom. 9, 365-371.

11) Kakimoto, Y., Nakajima, T., Kumon, A., Matsuoka, Y., Imaoka, N., and Sano, I. (1969) J. Biol. Chem. 244, 6003-6007.

12) Corzo, G., Gilles, N., Satake, H., Villegas, E., Dai, L., Nakajima, T., and Haupt, J. (2003) FEBS Lett. 547, 43-50.

13) Yamaji, N., Horikawa, M., Corzo, G., Naoki, H., Haupt, J., Nakajima, T., and Iwashita, T. (2004) Tetrahedron Lett. 45, 5371-5373.

14) Hirai, Y., Yasuhara, T., Yoshida, H., Nakajima, T., Fujino, M., and Kitada, C. (1979) Chem. Pharm. Bull. 27, 1942-1944.

15) Nakajima, T. (1986) In Venoms of Hymenoptera: Pharmacological biochemistry of vespid venoms (ed. Piek, T.). Academic Press, London, pp. 309-327.

16) Kuroda, Y., Yoshioka, M., Kumakura, K., Kobayashi, K., and Nakajima, T. (1980) Proc. Jpn. Acad., Ser. B 56, 660-664.

17) Higashijima, T., Uzu, S., Nakajima, T., and Ross, E. M. (1988) J. Biol. Chem. 263, 6491-6494.

18) Dai, L., Yasuda, A., Naoki, H., Corzo, G., Andriantsiferana, M., and Nakajima, T. (2001) Biochem. Biophys. Res. Commun. 286, 820 825 .

19) Hisada, M., Konno, K., Itagaki, Y., Naoki, H., and Nakajima, T. (2000) Rapid Commun. Mass Spectrom. 14, 1828-1834.

20) Hisada, M., Konno, K., Itagaki, Y., Naoki, H., and Nakajima, T. (2002) Rapid Commun. Mass Spectrom. 16, 1040-1048.

21) Konno, K., Hisada, M., Fontana, R., Lorenzi, 
C. C., Naoki, H., Itagaki, Y., Miwa, A., Kawai, N., Nakata, Y., Yasuhara, T. et al. (2001) Biochem. Biophys. Acta 1550, 70-80.

22) Konno, K., Hisada, M., Naoki, H., Itagaki, Y., Yasuhara, T., Juliano, M. A., Juliano, J., Palma, M. S., Yamane, T., and Nakajima, T. (2001) Toxicon 39, 1257-1260.

23) Corzo, G., Villegas, E., Gōmez-Lagunus, F., Possani, L. D., Belokoneva, O. S., and Nakajima, T. (2002) J. Biol. Chem. 277, 2362723637.

24) Corzo, G., Escoubas, P., Villegas, E., Barnham, K. J., He, W., Norton, R. S., and Nakajima, T. (2001) Biochem. J. 359, 35-45.

25) Tu, A. T. (ed.) (1984) Handbook of Natural Toxins, vol.2, Insect Poisons, Allergens, and Other Invertebrate Venoms. Marcel Dekker, New York - Basel.

26) Hagiwara, K., Sakai, T., Miwa, A., Kawai, N., and Nakajima, T. (1990) Biomed. Res. 11, 181-186.

27) Inui, T., Hagiwara, K., Nakajima, K., Kimura, T., Nakajima, T., and Sakakibara, S. (1992) Peptide Res. 5, 140-144.

28) Corzo, G., Escoubas, P., Stankiewicz, M., Pelhate, M., Kristensen, C. P., and Nakajima, T. (2000) Eur. J. Biochem. 267, 5783-5795.

29) Wu, J., and Watson, J. T. (1997) Protein Sci. 6, 391-398.

30) Skinner, W. S., Dennis, P. A., Li, J. P., and Quistad, G. B. (1992) Toxicon 30, 1943-1950.

31) Fletcher, J. I., Smith, R., O'Donoghue, S. I., Nilges, M., Connor, M., Howden, M. E. H., Christie, M. J., and King, G. F. (1997) Nature Structural Biol. 4, 559-566.

32) Kaiser, I. I., Griffin, P. R., Aird, S. D., Hudiburg, S., Shabanowitz, J., Francis, B., John, T. R., Hunt, D. F., and Odell, G. V. (1994) Toxicon 32, 1083-1093.

33) Lampe, R. A., Defeo, P. A., Davison, M. D., Young, J., Herman, J. L., Spreen, R. C., Horn, M. B., Mangano, T. J., and Keith, R. A. (1993) Mol. Pharmacol. 44, 451-460.

34) Escoubas, P., Diochot, S., Célérier, M.-L., Nakajima, T., and Lazdunski, M. (2002) Mol. Pharmacol. 62, 48-57.

35) Fajloun, Z., Kharrat, R., Chen, L., Lecomte, C., Di Luccio, E., Bichet, D., El Ayeb, M., Rochat, H., Allen, P. D., Pessah, I. N. et al. (2000) FEBS Lett. 469, 179-185.

36) El-Hayek, R., Lokuta, A. J., Arévalo, C., and Valdivia, H. H. (1995) J. Biol. Chem. 270, 28696-28704.

37) Corzo, G., Adachi-Akahane, S., Nagao, T., Kusui, Y., and Nakajima, T. (2001) FEBS Lett. 499, 256-261.

38) Tanaka, H., Sudo, C., An, Y., Yamashita, T., Sato, K., Kurihara, M., and Suzuki, K. (1998) Appl. Entomol. Zool. 33, 535-543.
39) Romi-Lebrun, R., Lebrun, B., Martin-Eauclaire, M. F., Ishiguro, M., Escoubas, P., Wu, F. Q., Pongs, O., and Nakajima, T. (1997) Biochemistry 36, 13473-13482.

40) Lebrun, B., Romi-Lebrun, R., Martin-Eauclaire, M. F., Yasuda, A., Ishiguro, M., Oyama, Y., Pongs, O., and Nakajima, T. (1997) Biochem. J. 328, 321-327.

41) Dai, L., Corzo, G., Naoki, H., Andriansiferana, M., and Nakajima, T. (2002) Biochem. Biophys. Res. Commun. 293, 1514-1522.

42) Bernard, C., Corzo, G., Mosbah, A., Nakajima, T., and Darbon, H. (2001) Biochemistry 40, 12795-12800.

43) Blanc, E., Romi-Lebrun, R., Bornet, O., Nakajima, T., and Darbon, H. (1998) Biochemistry 37, 12412-12418.

44) Renisio, J.-G., Romi-Lebrun, R., Blanc, E., Bornet, O., Nakajima, T., and Darbon, H. (1999) Proteins 8, 2672-2685.

45) Savarin, P., Romi-Lebrun, R., Zinn-Justin, S., Lebrun, B., Nakajima, T., Gilquin, B., and Menez, A. (1999) Protein Sci. 8, 2672-2685.

46) Yamaji, N., Dai, L., Sugase, K., Andriantsiferana, M., Nakajima, T., and Iwashita, T. (2004) Eur. J. Biochem. 271, 3855-3864.

47) Hisada, M., Satake, H., Masuda, K., Aoyama, M., Murata, K., Shinada, T., Iwashita, T., Ohfune, Y., and Nakajima, T. (2005) Biochem. Biophys. Res. Commun. 330, 1048-1054.

48) Strydom, D. J. (1977) Biochem. Biophys. Acta 491, 361-369.

49) Strydom, D. J. (1973) Nature New Biol. 243, 8889.

50) Schweitz, H., Heurteaux, C., Bois, P., Moinier, D., Romey, G., and Lazdunski, M. (1994) Proc. Natl. Acad. Sci. USA 91, 878-882.

51) Schweitz, H., Bruhn, T., Guillemare, E., Moinier, D., Lancelin, J. M., Beress, L., and Lazdunski, M. (1995) J. Biol. Chem. 270, 25121-25126.

52) Kassell, B., Radicevic, M., Ansfield, M. J., Laskowski Sr., M. (1965) Biochem. Biophys. Res. Commun. 18, 255-258.

53) Habermann, E., and Reiz, K. G. (1965) Biochem. Z. 341, 451-466.

54) Shipolini, R. A. (1984) In Handbook of Natural Toxins: Biochemistry of bee venom (ed. Tu, A. T.). Marcel Dekker, New York - Basel, pp. 4985.

55) Habermann, E., and Cheng-Raude, D. (1975) Toxicon 13, 465-467.

56) Grissmer, S., Nguyen, A. N., Aiyar, J., Hanson, D. C., Mather, R. J., Gutman, G. A., Karmilowicz, M. J., Auperin, D. D., and Chandy, K. G. (1994) Mol. Pharmacol. 45, 1227-1234.

57) Srinivasan, K. N., Sivaraja, V., Huys, I., Sasaki, T., Cheng, B., Kumar, T. K. S., Sato, K., Tytgat, J., Yu, C., San, B. C. C. et al. (2002) J. 
Biol. Chem. 277, 30040-30047.

58) Chagot, B., Pimentel, C., Dai, L., Tytgat, J.,
Nakajima, T., Corzo, G., Darbon, H., and Ferrat, G. (2005) Biochem. J. 388, 263-271.

(Received Aug. 24, 2006; accepted Sept. 20, 2006)

\section{Profile}

Terumi Nakajima, born in 1933, finished the doctoral study at the Faculty of Pharmaceutical Sciences, the University of Tokyo, and started his research career in 1960 with studies on analytical chemistry of biological materials. In 1971, he moved out to Hiroshima University, School of Medicine as a professor, and focused his research targets on the investigation of bioactive peptides in the cutaneous glands of the amphibians and on the microanalysis of venomous principles in the wasp venom. He moved to the Institute for Medical and Dental Engineering, Tokyo Medical and Dental University in 1980, and continued his research on toxinology. He was promoted to Professor at the University of Tokyo in 1983 and became Dean, Faculty of Pharmaceutical Sciences in 1990. After retirement from the University of

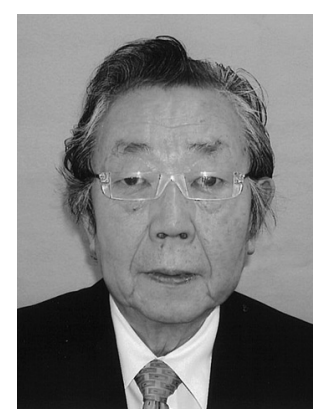
Tokyo, he accepted both calls of the positions Senior Managing Director, Member of the Board, Suntory Limited and Director, Suntory Institute for Bioorganic Research in 1994. During this period of research, he visited several times to Ryukyu Island, Papua New Guinea and Madagascar to collect venomous arthropods. He was awarded the Japan Academy Prize in 1994 for his pioneering studies on the spider toxins. He is an honorary member of the Pharmaceutical Society of Japan, the Japanese Biochemical Society, and the Japanese Peptide Society. At present he is President of Hoshi University. 